\title{
Possibilities of using energy recovery in underground mines
}

\author{
Dariusz Obracaj ${ }^{1}$, and Sebastian Sas $^{1, *}$ \\ ${ }^{1}$ AGH University of Science and Technology, Faculty of Mining and Geo-engineering, $30 \mathrm{~A}$. \\ Mickiewicz Av., 30-059 Kraków, Poland
}

\begin{abstract}
In underground mines, there are many sources of energy that are often irrecoverably lost and which could be used in the energy structure of a mine. Methane contained in the ventilation air, the water from the dewatering of the mines and the exhaust air from the mine shafts are the most important sources of energy available to a mine. Among other sources of energy available in a mine, you can also distinguish waste energy from the process of the desalination of water or energy from the waste. The report reviewed the sources of energy available in a mine, assessed the amount of recoverable energy and indicated the potential for its use.
\end{abstract}

\section{Introduction}

The mining industry is one of the most energy-intensive industries in Poland [1]. High energy consumption translates into increased production costs, indirectly affecting the profitability of an underground mine. One of the energy-consuming energy systems of a mine is the installation of inlet air heating to the mine. This paper presents theoretical possibilities of extracting energy from the ventilation system, mine drainage, methane drainage and other sources of energy for heating the air introduced into a mine, analyzing theoretical possibilities of recovering waste heat from the ventilation shaft.

\section{Heat recovery from ventilation air}

A method of recovering heat and preheating the inlet air into a mine is the use of a cross-plate heat exchanger "GUPEX" (Fig. 1). Cold air passes through the heat exchanger taking away heat from the warm air removed from the mine. The heat exchanger may be part of the mine ventilation system, which requires an air flow of up to several million $\mathrm{m}^{3} / \mathrm{h}$. Thousands of kilowatts of heat are continuously transferred to the cold air entering the mine, which saves significant amounts of energy. The heat exchangers are made of corrosion-resistant material, which is of particular importance because of the high moisture content in the air. Heat exchanger plates are designed to cause a low-pressure drop and to minimize fan power consumption.

\footnotetext{
Corresponding author: ssas@agh.edu.pl
} 


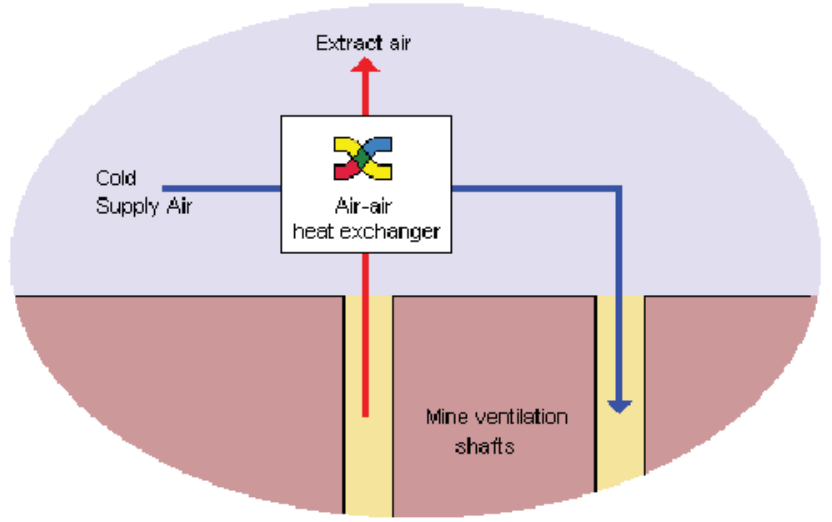

Fig. 1. Principle of operation of cross-plate exchanger for recovery of heat from the air removed from the mine [2].

\section{Heat recovery from mine water}

Polish literature lacks information on the use of energy derived from mine water as a source of energy. There are some references to the assessment of the heat recovery capacity of coal mines, in the "GIG" documentation [3], but these materials have not been published. In international journals, however, there is no shortage of examples of the use of energy from mine waters. The example from Stockholm [3] shows that even from water at $4^{\circ} \mathrm{C}$, energy can be recovered by cooling it to $2^{\circ} \mathrm{C}$.

An example of a mine water installation is located in England at the non-existent Caphouse mine located in Overton near Wakefield. The installation diagram is shown in Fig. 2.

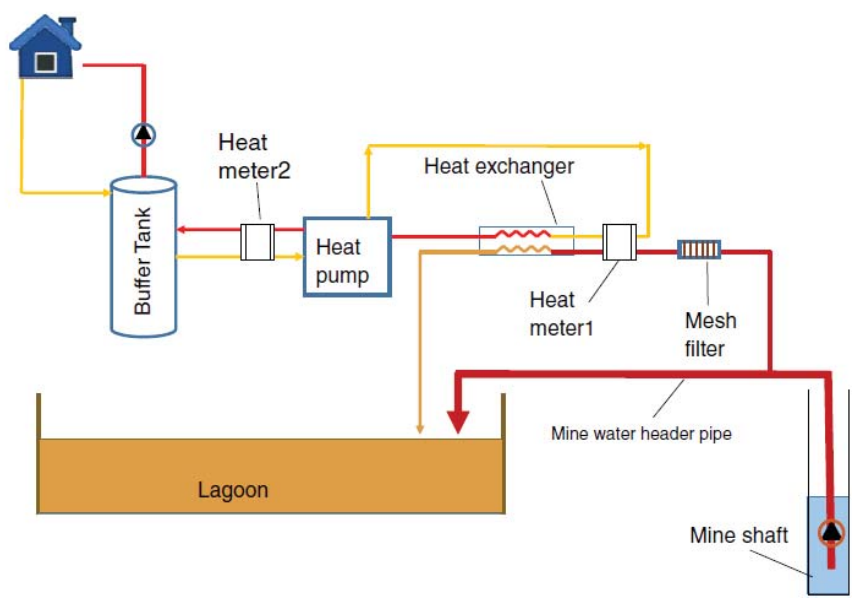

Fig. 2. Simplified diagram of heat recovery installations from mine water [4].

The heart of the installation is the heat pump which receives the energy transferred through the heat exchanger from the water pumped out of the mine. Due to the small size of the system, a part of the water discharge is transferred directly to the tank, while the remainder is directed to the heat exchanger where the heat exchange in the closed loop is carried out. Water circulates between the heat pump and the exchanger to which the water is to be drained. Due to the low quality of the mine water, characterized by high salinity, 
3xidizing pyrite and the possibility of clogging of the exchangers in the system, two water filters are operated alternating during the maintenance periods of one of them, resulting in the possibility of the continuous operation. A heat pump used successfully in the summer with an average water temperature of $14.5^{\circ} \mathrm{C}, \Delta \mathrm{t}=5-6^{\circ} \mathrm{C}$, achieved COP efficiency between 3.5 and 4.5 at $\Delta \mathrm{t}=5^{\circ} \mathrm{C}[5]$.

\section{Energy from cogeneration systems}

Most of the captured methane is processed energetically in cogeneration systems in the Polish mining sector. These systems permit the generation of electricity and the recovery of the so waste heat that can be used to heat hot water, process steam, or to heat buildings.

Methane entrained in the drainage systems can also be used in existing gas boilers or cofired in coal boilers.

The most economically justified system 3 tilizing methane is now a tri-generation system that simultaneously produces three energy carriers in the form of power, heat and cooling (CHCP).

In Poland, the CHCP system works only in the "Pniówek" mine and a second trigeneration system is being prepared for work in the mine ZG Rudna Polska Miedz S.A. The installation is based on the combination of heat and power distribution system with a cooling system. The gas engine drives generators that produce electricity that is fed to the power system of the mine. Waste heat is used as drive energy in absorption chillers that provide cooling power for the central air conditioning system of an underground mine.

Less common solutions used in mines are, among others, gas turbines and microturbines that can be an alternative to gas engines. Their principle of operation is very close to each other. However, the microturbines are rarely used because of the relatively small output power [6].

\section{Waste energy from other energy sources}

Apart from the primary sources of waste energy mentioned in the above subsections, another source of heat that can be used as waste energy is the heat from the mine waste.

Coal waste sheds include at least a few percent of the carbonaceous and pyrite additives that cause them to slowly oxidize. The temperature inside the oxidizing dump can exceed the temperature of $600^{\circ} \mathrm{C}$, where it has been tested at a depth of several meters at $250^{\circ} \mathrm{C}$ while the surface is overgrown with grass. Heat from the heap can be used for municipal purposes and the fired heap is used as a source of aggregate or clay shale or for recreational purposes. The proposed solutions to the problem of heap nuisance with the simultaneous reception of their thermal potential can be used in two main ways:

- burn the heap with simultaneous heat and then use it as a source of aggregate,

- burn out the heap with simultaneous heat reception and then afforestation and use as a recreational facility.

Heat from the heap can be exploited successively by passive heat transfer or by the active method using heap heater. Heat reception can take place using closed circuit heat exchangers, and heat transfer from the primary circuit to external heat exchangers can be held on the production head or the heater area near them [7]. A critical danger, however, which may arise during the migration of heat is the ignition of the heaps. Therefore, it is a useful further analysis of this method, to provide adequate insulation of the transported heat by insulating it from the rest of the heap.

Another important source of energy is the heat generated by the desalination of mine waters, which is a troublesome waste that can be economically exploited throughout the year. 
Desalination involves the production of large amounts of clean waste water at $40^{\circ} \mathrm{C}$. These waters cannot be disposed of by direct discharge into the open water because of their high temperature. Hot water could be used as the lower energy source for the heat pump or as a source of energy for heating the primary water supply, for example, hot water.

\section{Cost and power needed to heat the inlet air}

Heating the air supplied to mine shafts requires a large amount of thermal energy and generates considerable costs, the qualified majority as fixed costs (independent of production). The economic aspect should, therefore, be an incentive to modernize and streamline heating systems, particularly in the mining industry, which is characterized by high energy consumption. Figure 3 presents a graph of energy demand for inlet air heating from $-20^{\circ} \mathrm{C}$ to $1^{\circ} \mathrm{C}$. The chart shows that the peak demand for power in the case of a temperature of $-20^{\circ} \mathrm{C}$ is about $17.2 \mathrm{MW}$ for the largest inlet air stream of $35,000 \mathrm{~m}^{3} / \mathrm{min}$. Taking into account the statistical temperature distribution throughout the year, so much power demand is only required a few hours a year, plus these temperatures would not necessarily occur at the same time. The figure shows that the greatest deflection of the curve is observed in the number of hours of 80 . For this value, the power demand is significantly smaller, because it is about $9 \mathrm{MW}$, which suggests that the peak demand theoretically could be an average of one hour each day during the whole heating season. It is therefore important to consider whether it is worthwhile to build a double-power installation just to provide air heating in such a short period, or to build a lower-power installation and an alternative system that would provide additional power at peak moments. Figure 4 shows the total Giga-hour energy demand $(\mathrm{GWh})$ for the given air streams and may be the starting point for calculating the energy costs needed to heat inlet air. Figure 5 shows the instantaneous power requirements for the inlet air heating depending on the airflow and the temperature gradient between the expected temperature of $1^{\circ} \mathrm{C}$ and the outdoor air temperature in the mine [8-10].

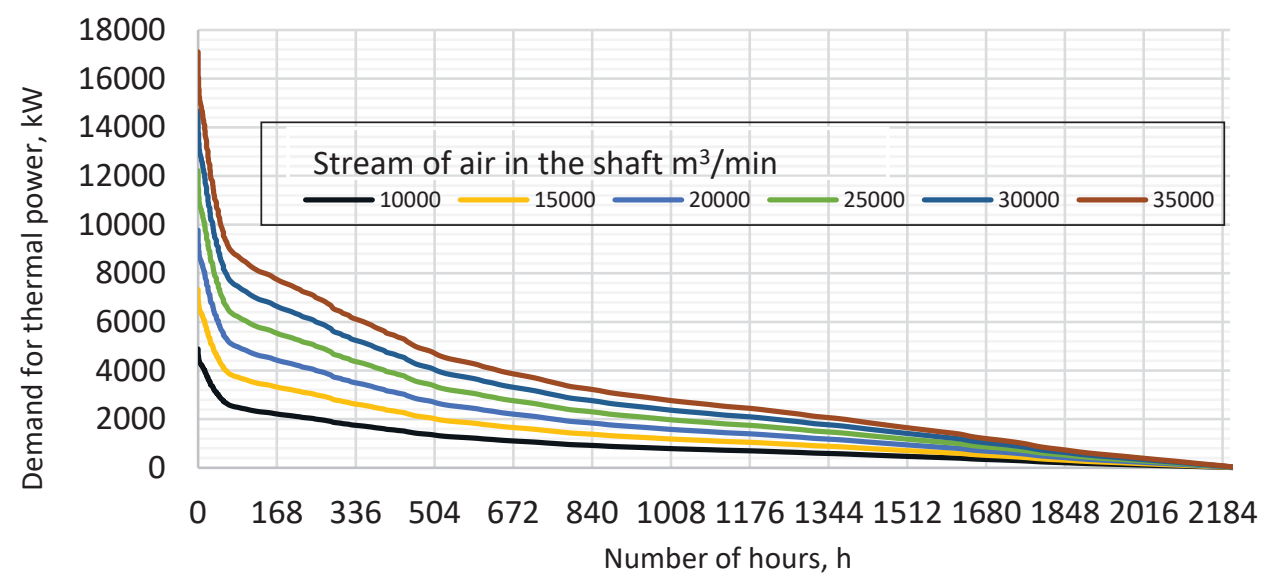

Fig. 3. Power demand curve for inlet air heating in the downcast shaft. 


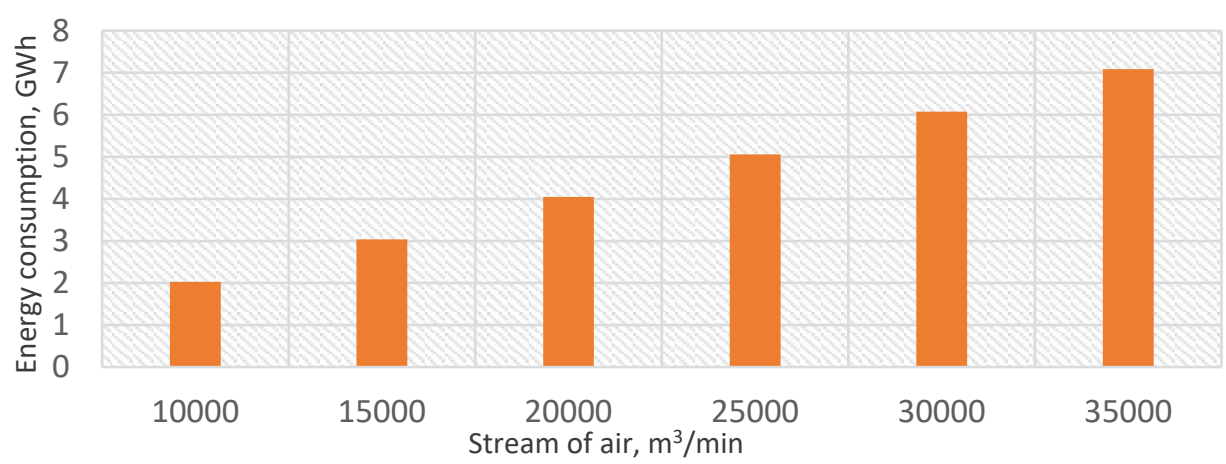

Fig. 4. Graph of GWh energy consumption for inlet air heating.

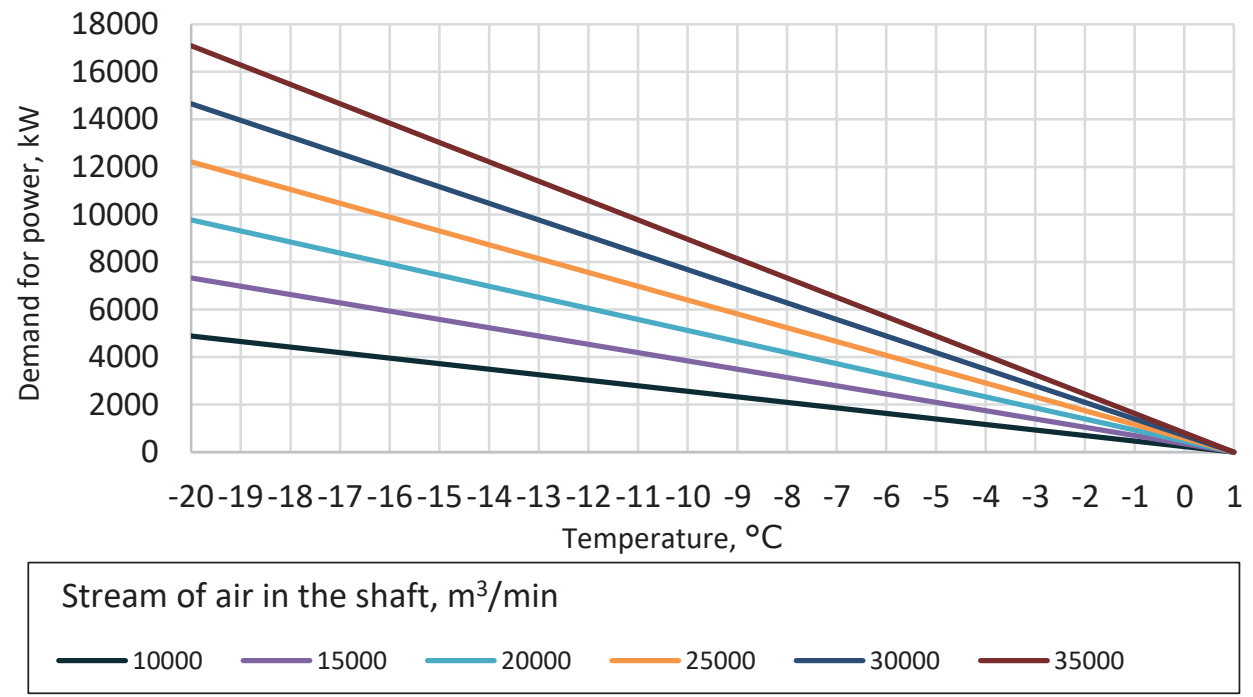

Fig. 5. Demand curve for the power needed to heat the inlet air.

\section{Possibilities of using air exhausted by upcast shafts}

The thermodynamic parameters of the exhaust air are shaped by many complex processes of heat and mass transfer. The heat transfer between the strata and the mining excavation is carried out explicitly by thermal conductivity, radiation, convection, and by evaporation or condensation (latent). With the air flow downward, the air is compressed, and when the ascent moves its expansion. Pressure reduction (without heat exchange) is accompanied by a decrease in temperature, while its increase increases the temperature. The values of heat transfer from rock to air depend on many factors such as:

- the depth of which the excavation is located, and the associated primary temperature of the rocks,

- the temperature of the flowing air and its change over time,

- geological construction of surrounding rocks, (physical properties of rocks, such as heat capacity, density, thermal conductivity coefficient),

- geometric dimensions of the shaft,

- period of ventilation,

- the flow and velocity of air flow, 
- exchange of moisture and change of concentration of moisture contained in air,

- heat emitted from devices occurring in the windshield,

- the wall roughness caused by the unevenness of the shaft [8].

The air flowing through the excavation is generally at a different temperature than the surrounding rocks. The gradient of this value causes heat flow. Heat transfer in rocks is carried out by thermal conductivity. Rocks around the excavations to which atmospheric air enters are some kind of heat generator. In the summer, when the warm atmospheric air heats the rocks, the air cools, while in the cold, the cold air cools the rocks away from them, causing the seasonal fluctuations in the temperature of the mine air to decrease. These variations increase in the glazing, while in the excavations temperature changes are usually small. An example of an average expenditure and temperatures measured in the SW-VI-Jas exhaust shaft is shown in Figure 6.

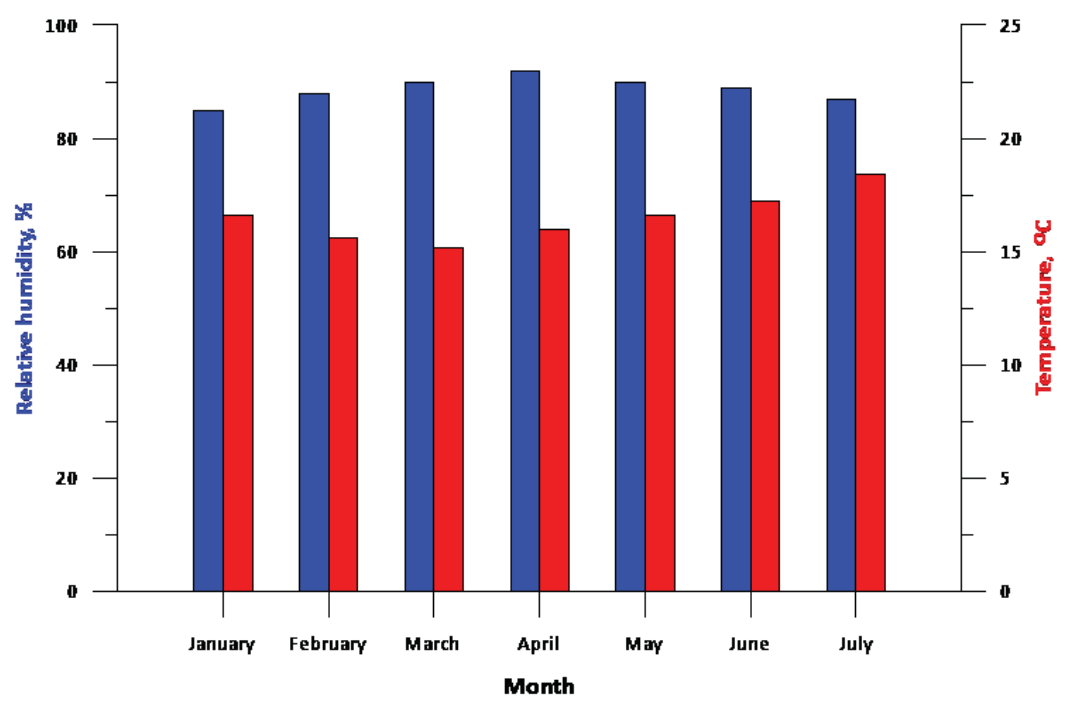

Fig. 6. Graph of mean temperature, humidity and in the upcast shaft in Jas-Mos mine [6].

The large energy potential of the mine removed from the mine in both summer and winter time can be used as the bottom source of energy by using the heat pump as an intermediate unit for the exchange of heat between the exhaust air and the mine.

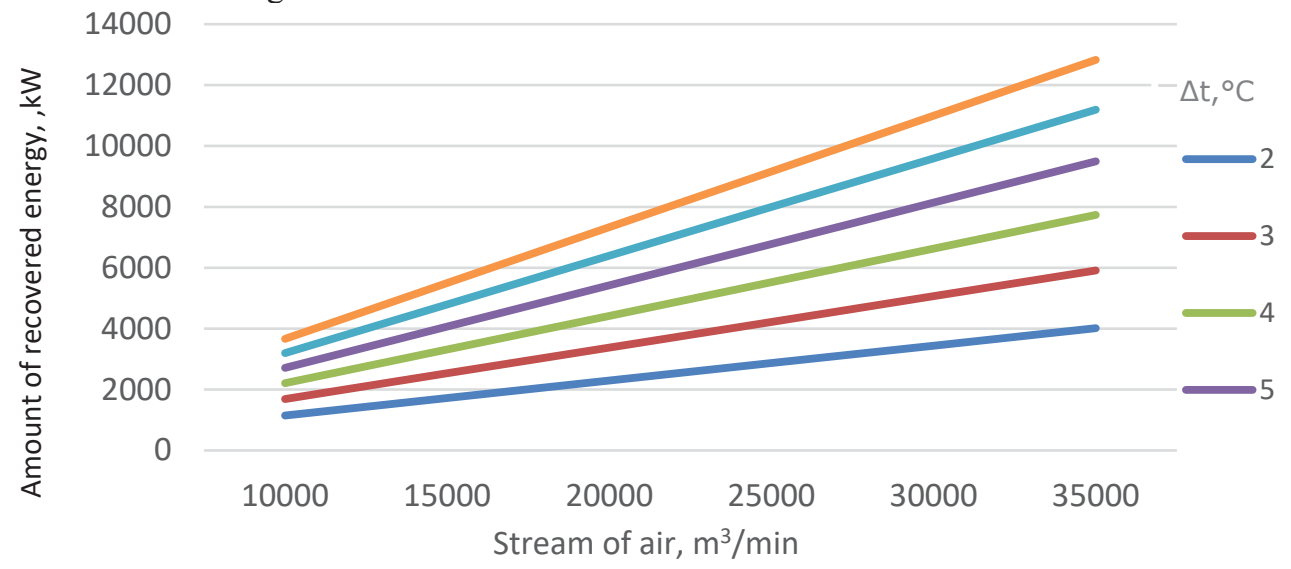

Fig. 7. Heat power obtained from the exhaust air from the upcast shaft as a function of airflow for variable differences of temperature. 
Based on Figure 6, in the winter, the air stream has an oscillating temperature of $16^{\circ} \mathrm{C}$, which allows for complete heat utilisation. The possibility of using waste heat could consist in mounting a heat exchanger in the ventilation drift in front of the main fan station or by using a bypass passage that would include an additional fan and a heat exchanger. The collected heat would be transferred to the upper source of heat which would be used to heat the water used to heat the inlet air $[8,9,11]$. Figure 7 presents a graph of the possibility of extracting heat from the exhaust air from the mine, depending on the gradient of temperature and airflow. Consistent with this figure, a power of $4 \mathrm{MW}$ can be obtained for an air flow of $35,000 \mathrm{~m}^{3} / \mathrm{h}$ and a difference of $3{ }^{\circ} \mathrm{C}$ between the exhaust air and the exchanger wall temperature. With a temperature difference of $5^{\circ} \mathrm{C}$, approximately $9.5 \mathrm{MW}$ of power can be obtained. These values are significant considering the peak demand for $17 \mathrm{MW}$ thermal power for heating inlet air at $-20^{\circ} \mathrm{C}$.

\section{Conclusions}

Actual demand for inlet air heating depends on current outdoor temperature conditions. From the ordered temperature chart for Katowice (Poland), the extreme air temperatures of less than $-10^{\circ} \mathrm{C}$ are very rare throughout the heating season. They are only 26 hours according to the meteorological station in Katowice.

For heating the air enters the mine shaft, the heat power is about $12 \mathrm{MW}$ for a volume flow rate of $35,000 \mathrm{~m}^{3} / \mathrm{h}$ at the ambient temperature of $-20^{\circ} \mathrm{C}$. If the ambient temperature is $-10^{\circ} \mathrm{C}$, the power demand is approximately $6.2 \mathrm{MW}$.

You can use the heat from the mine exhaust air to heat the air to the coffin using a heat pump. For an air flow of $35,000 \mathrm{~m}^{3} / \mathrm{h}$, approximately $9.5 \mathrm{MW}$ of power can be obtained assuming the temperature difference $\Delta \mathrm{t}=5^{\circ} \mathrm{C}$ on the heat exchanger. For heating the circulating water, a heat pump can be used in the heat exchanger circuit.

The use of a heat pump as an indirect source of heat transfer between the exhaust air and the inlet air to the coals can be achieved by providing many savings in constant flow and $\mathrm{CO}_{2}$ burning, which is undoubtedly a pro-ecological solution.

The problem to solve is the technical aspects of system design for heat exchange reliability. It is also necessary to minimize exchanger air resistance, which is crucial for the safety, failure-free and safe co-operation of main ventilation fans with the mining ventilation network.

\section{References:}

1. J. Kott, M. Kott, Z. Szalbierz, Management and Finance, R. 10, nr 1, part 2, 585-593 (2012)

2. http://www.gupex.com/article.aspx?id=93224 (access: 15.06.2017)

3. E. Solik-Heliach, Research Reports Mining And Environment 2/2002, 17-24 (2002)

4. A.P. Athresh, A. Al-Habaibeh, K. Parker, International Journal of Coal Geology, Vol 164, 69-76 (2016)

5. E. Ostrowska, L. Ośródka, Materials of the 36th National PTG Congress, part II, Sosnowiec (1987)

6. N. Szlązak, M. Borowski, D. Obracaj, J. Swolkień, M. Korzec, Methane drainge in coal mines (AGH University of Science and Technology Press, Cracow, 2015)

7. A. Dybciak, Z. Heliasz, S. Ostaficzuk, Works of the Department of Basic Geology, Faculty of Earth Sciences, Silesian University, Sosnowiec, 119-128 (2000)

8. J. Wacławik, Ventilation of mines $t$. 2, Edition: 1 (AGH University of Science and 
Technology Press, Cracow, 2010)

9. J. Pawiński, J. Roszkowski, J. Strzemiński, Ventilation of mines (Silesian National Publishing House. Katowice, 1995)

10. N. Szlązak, L. Kloc, Influence of heating air in downcast shafts on the stability of fair streams in coal mine ventilation network (AGH University of Science and Technology Press, Cracow, 2004)

11. M. Rubik, Heat pump, Information center, Installation technique in construction (Warsaw 2006) 